\title{
Destroying hills in the northeastern part of Bangladesh: A qualitative assessment of extent of the problem and its probable impact
}

\author{
${ }^{1}$ Md. Sirajul Islam, ${ }^{2}$ G. M. Jahid Hasan and ${ }^{3} M d$. Aktarul Islam Chowdhury \\ ${ }^{1}$ Department of Environmental Science and Management, North South University, Banani, Dhaka, Bangladesh \\ ${ }^{2}$ Takewaka Laboratory, Graduate School of Systems and Information Engineering, University of Tsukuba, Tennodai 1-1-1, \\ Tsukuba, Ibaraki 305-8573, Japan \\ ${ }^{3}$ Department of Civil and Environmental Engineering, Shahjalal University of Science and Technology, \\ Sylhet-3114, Bangladesh \\ Received 16 September 2005; \\ revised 10 November, 2005; \\ accepted 25 November 2005
}

\begin{abstract}
Indiscriminate cutting of hills in the Sylhet region has become a major environmental issue. The nature and life style of Sylhet intimately related with the hills are thus under the threat of a drastic imbalance in its ecosystem. Due to such hill cutting the mostly affected sectors of this region will be its weather and climate, geomorphology and hydrology, and the indigenous flora and fauna. As a result the frequency of natural calamities like earthquake, flash flooding etc may increase considerably. Deforestation and resulting increased soil erosion, decreased ground water recharge and deteriorated water quality might also be as consequences of such hill cutting. This paper investigates the cause and extent of the problem along with its probable impact and finally suggests actions for conservation of hills for ecological balance of the region.
\end{abstract}

Key words: Hill cutting, extent of the issue, probable impact, legal aspects, Sylhet

*Corresponding Author, E-mail: hasan@surface.kz.tsukuba.ac.jp

\section{INTRODUCTION}

Sylhet, the north-eastern administrative division of Bangladesh (Fig. 1), located at $24^{\circ} 53^{\prime}$; latitude and $91^{0} 52^{\prime} \mathrm{E}$ longitude, has a number of topographical features like hills and hillocks (tilas), haors (wetland) and high flood plain; which made it quiet different from the rest of the parts of Bangladesh. The region is also endowed with most of the natural resources available in Bangladesh like gas, oil, limestone and diversified forests. Hilly Sylhet region not only plays an important role in the socio-economic development of Bangladesh but also important for ecological balance of the country. Beautiful panorama of the region with vast reserve of forest, intense tea gardens and growing rubber gardens in the hillocks, lakes and wetlands as well as sands and stones of the boarder areas made it attractive for tourists from both home and abroad. Among the topographical features of the region, however, hills are the most dominating one, which is determining its climatic and morphological features. Heavy rainfall, tea garden, dense bamboo and cane bushes, high flood plain and the flashy rivers; all the features are very related and contributed by the hills of this region. The life style and agricultural pattern of the people of this region thus grew up in conforming to such geographical and climatic condition. It is obvious that any sort of mishandling of the hills will make the ecosystem of this region complicated. In this connection, it is quite unfortunate to note that in recent years the region is suffering from indiscriminate destruction of the hills i.e. its unique topographic features. Destruction of hills is occurring in different scales for different purposes. The paper likes to investigate the issue for specific causes and probable consequences considering it as a serious threat to the ecological imbalance of the region. This Study have been done in Sylhet region of Bangladesh in 2003.

\section{MATERIALS AND METHODS}

Sylhet region has a significant numbers of hills all around. Small areas of the Meghalaya Plateau foothills fall within Bangladesh situated mostly near the border areas of Sylhet (Fig. 1). However, small hills, 
locally known as tilas are found scattered at many places along the Sylhet city up to Srimangal and Maulovibazar. Height of the hills of this region ranges from 60 to 150 meters and the tilas ranges from 30 to 90 meters. According to Brammer (2002) the geological formation is mainly of pliestocene era and soil type is slightly acidic.

Haor basin extends from two rivers to the high plain of central Sylhet. This basin covers an area of 4505.20 sq. $\mathrm{km}$. A major part of this basin is developed due to the earthquake of 1762 . Haor basin goes under water for several months and the soil condition of it is clay with loams.
The flood plain is higher at this region than the rest of the part of the country. The flood plains cover the lands of above $9 \mathrm{~m}$ high. It also includes beels and haors of height above $9 \mathrm{~m}$ and most of these beels and haors drain out in early winter.

Northern branch of river Barak (comes from India) gets the name Surma which is one of the main river of Bangladesh passed through Sylhet city. Southern branch of Barak gets the name Kushiara in Bangladesh, which is another major river of Sylhet. Surma and Kushiara make unification as Kalani, which is renamed as Meghna and finally merges with the Bay of Bengal.

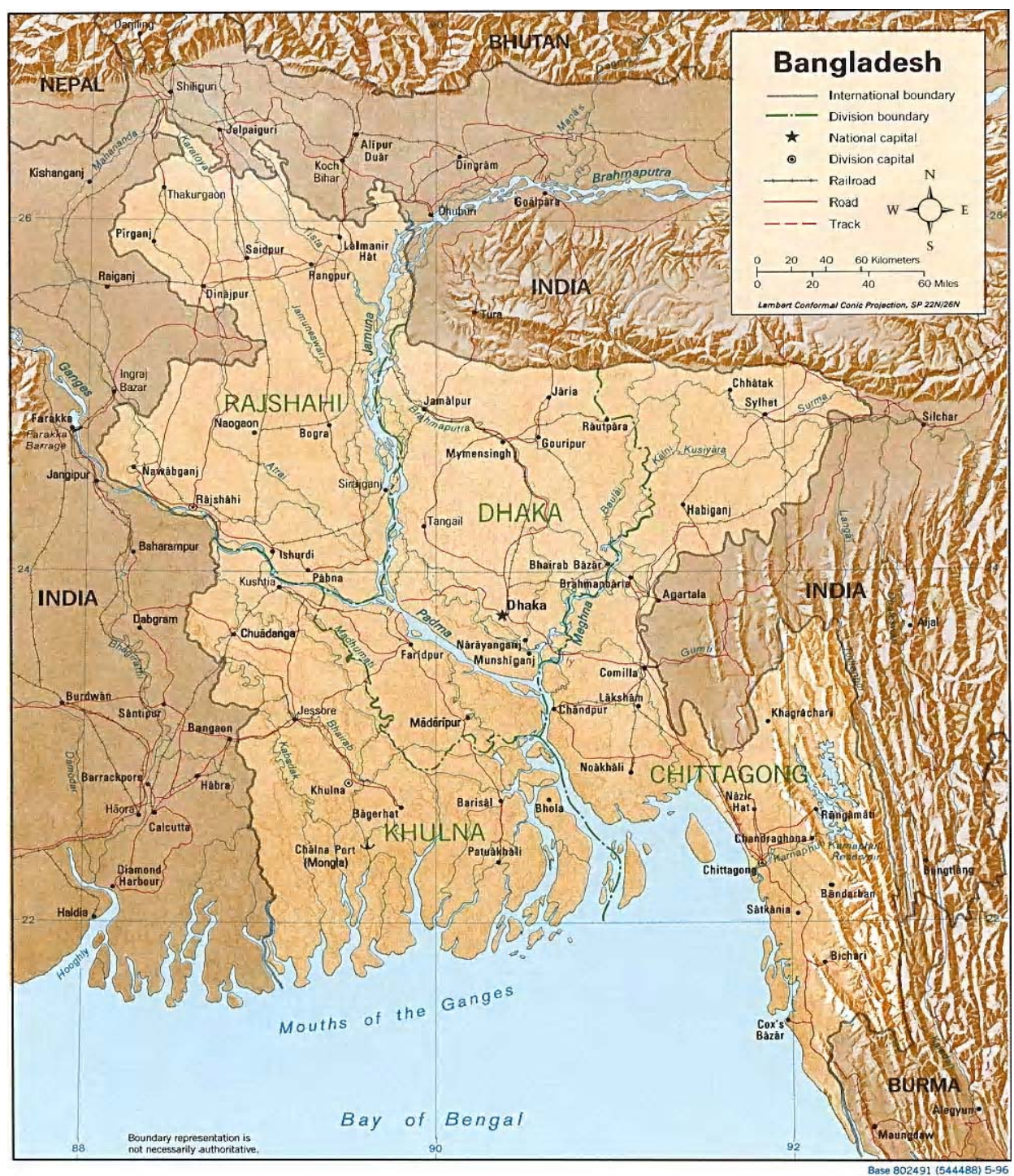

Fig. 1: Topographic relief map of Bangladesh showing the studied area 
Other important rivers are: Mogra, Dhanu, Boulai and Ghorautra. Main characteristic of rivers of this region is flashy and flash flood occurs frequently during May to the middle of October. The networks of the rivers, streams and channels overflow in the rainy season and fill the haors at the early part of rainy season.

\section{Climate}

The temperature and rainfall data has been collected from the Meteorological Department of Bangladesh and showed in Table 1. It is observed that the summer is becoming hot nowadays and reverse in winter. However, the average annual rainfall is also reducing. Destroying hills may have some effects on this weather changing which is hampering the ecosystem in this region seriously.

Sylhet region is rich in forest with diversified flora and fauna. The distribution of forest of Sylhet region is: Reserved forest (124.94 sq. km), Acquired forest (71.80 sq. km), Un-classed forest (56.70 sq. km), Khas forest (12.61 sq. km) and Private forest (32.22 sq. km) by Rashid (1991). Major forest and corn resources are: Bamboos and Canes; Hijal, Jam, Jarul; Nol kagra and Ekra reeds; Tea, Rubber and Coffee in hillock areas; Potato, Pineapple, Jackfruits, Chillis, Tobacco, Mustard, Bettle leaf; Paddy and vegetables etc.

Besides different types of snakes, wild animals like monkey, flying fox etc are found in the hilly forest of Sylhet region. Numerous types of birds and fishes are also available abundantly in the haors and rivers.

It becomes a burning question for the Sylhet region that nowadays people are indiscriminately destroying the hills. The most affected region is just near the Sylhet city. Hill cutting along Srimongal and Maulovibazar is also observed. It is estimated that every year about 5 to $12 \%$ of the total hills and tillas are cut or destroyed in different forms at different parts of the region (SDF, 2001). Already mentioned that hills of Sylhet are very related with its geographical and hydrological features. Forest ecosystem, wetland, high flood plain or hydroclimatic features of the region are some of the factors mostly related to the hills for determining the ecosystem interactions of the study region. The study of the impact on ecosystem was mainly aimed at finding probable interactions between the above factors with the hills. However, at the first place it is necessary to investigate why people are destroying the hills and how is the problem escalating. So there are two main parts of the study adopted, as;
1. Investigating the cause and extent of the problem 2. Determining its impact on the ecosystem.

Although any impact study needs huge amount of data of long span from different relevant sectors, the data availability of the relevant study is not of ample magnitude to support a detailed phenomenon as the study is at the initial stage of investigating theoretical aspects of the impacts related to hill cutting effects.

In a poverty stricken country like Bangladesh, the main reason for hill cutting is to search for new agricultural land or residential areas to fed or accommodate the country's fastest growing population. The forms of such destruction also varies in different forms like simply uncovering the hills from its natural vegetation covers and change it with new type of crops or trees, or in an extreme case of completely destroying it and flattened for residential, agricultural or other development purposes. In this connection some socio-economic reasons also played important rule. Historically Sylhet is a region having considerably better economic condition or per capita income compare to the rest of the parts of Bangladesh. A large percentage of expatriates from Bangladesh are from the Sylhet region. Because of such a high standard of living, especially in the Sylhet city area, there is an acute crisis of low wage working people like house maid, rickshaw puller or day labor etc that are mostly migrated from other cities. These low wage income groups are actually a type of floating people with no permanent house or even have the capability to rent a house. In most cases they built house near the hills, or try to increase their income by cultivating in the hill slopes. Some homeless poor people from different parts of Bangladesh even migrate in Sylhet only with a hope to survive in the hills by cultivating in its slopes and valises.. From the above figures, though it sounds that the main reason for hill cutting is poverty, but in actual case, sometimes-rich people are doing even more serious harms to the hills and at a larger scale. It has been observed that the rich people were destroying hills for their vested interest like real estate business, brick manufacturing, large-scale agriculture or filling land for road construction etc. The real state developers are cutting hills as in filling up lakes and water bodies to recover land for their questionable enterprise. Despite the laws, they do not face much obstacle and sometimes even receive permission for cutting hills. The small hillocks in the Sylhet region near localities are the best choice for rich people to build a luxurious house. Some 
of the economic and agricultural products like tea, rubber, pineapple, jackfruit etc are especially suitable to produce in the highland of the Sylhet region. Many big firms are grown up for the purpose of producing the above crops destroying hills. In this form of destruction, they are mostly destroying the forest over the hills, and planting it with different crops.

Cutting hills simply for collecting soil for land fill or construction purposes are one of the most serious form of destruction observed all along the region. The main interpretation of the causes for hill cutting and its extent are based on media reports, public concern, personal communication to some of the hill cutters and government officials and a few number of field trips.

At a state, while the destruction of the hills were looming large in an unrestricted way, government had taken initiative to impose legislative sanctions for those miscreants under the law started from 1995 and later amended in 2000 (DOE, 2002). The summaries of the law can be described as:

1. Nobody can cut and/or raze hills/tillas without prior permission,

2. Otherwise according to law he will be punished 10 years imprisonment or 10-lakh taka $[\$ 15,400]$ monetary punishment or both,

3. The government can give approval to hill cut/raze through a committee's approval whose head will be DC (highest ranked administrative officer in a district) and the main criteria for such approval are:

a. The cutting or razing of the hill shall not cause any serious damage to any hill, building, structure or land adjacent to or in the vicinity of the hill, or

b. The cutting or razing of the hill shall not cause any silting of or obstruction to any drain, stream or river, or c. The cutting or razing of the hill is necessary in order to prevent the loss of life or property, or

d. The cutting of the hill is such as is normally necessary for construction of dwelling house without causing any major damage to the hill, or

e. The cutting or razing of the hill is necessary in the public interest.

4. Approval fee for hill cutting/razing: the fee is at least Tk10,000 (\$165) or for bigger area 10,000 per "bigha” $\left(1335.5 \mathrm{~m}^{2}\right)$. The above laws for preventing hill cutting are quite attractive and adorable. However, it is unfortunate that still it could not prevent destruction of hill as a whole.

The law permits cutting or razing of hills with permission and fee. However, it is not clearly defined under what circumstances it will be permitted, but put in the hand of a committee. The above ruling thus makes scope for corruption. Lack of adequate knowledge of the consequence of hill cutting is another important factor that leads a committee member to be motivated for allowing it to cut with the understanding that instead of making the hill barren let it be used for beneficial purposes like housing or agriculture and get money as permission fee. However, the most serious drawback of the above laws might be the lack of provision of adequate monitoring. It is not clear who is in charge of monitoring the hill cutting incidents. Law enforcing authorities like police, forest department or the department of environment are the authorities heard to be conducting the duties, however, none of them are specifically assigned or trained for the purposes. In the close proximity to localities, even local people can inform police or district administration of the incident, but in a remote area there is no one to monitor it. The only scientific basis for such surveillance should be GIS based processed arial photographs that are taken at an interval of time. Such photographs taken at an interval can easily detect changes in the topography; including the way or in magnitude the changes occurred. In absence of such GIS based information, it is actually impossible to locate the destruction site.

\section{RESULTS}

The direct and probable impacts due to destroying hills require a detailed Environmental Impact Assessment (EIA) study. However due to limitation of available data, this study can be considered as a descriptive EIA study based on available information and theoretical background of cause and effect relationship. Depending on the topography, land use and hydro-climatic features of the Sylhet region, major effects of cutting hills can be grouped as follows:

A. Deforestation, Desertification and Biodiversity,

B. Ecological imbalance and climatic change,

C. Impact on morphology and water resources.

Detail explanations of the ecological interactions of the above groups and how they are disturbed by the destruction of hills are described in the following sections:

\section{Deforestation}

Deforestation is occurred due to hill cutting is either in direct or indirect form. Direct effects are as the trees and grasses over the hills are destroyed. Due to cutting 
hills the surface areas are reduced and the fertile topsoil with enriched nutrient and biomass are destroyed, which can be considered as indirect effect. In this case, because the temperature and nutrient content of the soil changes, it greatly affects the physico-chemical and biological processes in the soil i.e. the generation of seeds, normal growth of roots etc (John, 1990). In the study area it has been observed that further growth of plants and trees from the cut portion of the hill takes long time or almost absent in many cases.

\section{Desertification}

Desertification is occurred due to climatic changes or abusive land use. Improper lands use like removal of vegetal cover brings about marked changes in the local climate of this area. Thus, deforestation can change rainfall, temperature, wind velocity, etc and also leads to soil erosion. Such changes then lead to desertification of this region and the changing weather has already been observed in this region (Table 1).

Table 1: Average temperature and rainfall data of Sylhet region

\begin{tabular}{|ccccc|}
\hline Year & Maximum & $\begin{array}{c}\text { Minimum } \\
\text { winter temp. }\end{array}$ & Year & $\begin{array}{c}\text { Annual } \\
\text { rainfall } \\
(\mathrm{mm})\end{array}$ \\
\hline $1971-1980$ & 36.6 & 9.7 & $1957-1977$ & 4177.1 \\
$1981-1990$ & 37.3 & 6.4 & $1981-1991$ & 3880.0 \\
$1991-2000$ & 38.8 & 6.9 & $1992-2002$ & 3856.2 \\
\hline
\end{tabular}

\section{Biodiversity}

Hills give shelter to many species of life; ranging from tiger to birds or snakes, etc. Hill cutting will affect on their movement and shelter. It will also hamper the food chain among different species of life, killing some species or pushing them away. As a consequence their interdependency for food will break and life will be endangered (Colinvaux, 1995). It has been already noticed that many species of forest animal are nowadays becoming rare in the Sylhet region. Tigers are almost lost or rarely seen in the Sylhet region. Different types of monkeys were also endangered. Also, a large number of species specially takes shelter in the pores of the soil of hills. Due to destruction of hills, they will be abolished.

One of the main causes for earthquake is due to imbalance of any part of the crust of the earth. It might be inside or over the crust, but will leave the same effect. After destroying the hills, imbalance forces occurred because the pressure on the earth from the weight of hill has been changed. Such conditions obviously increase the possibility of earthquake. Depending on its geographical location, Sylhet is also a region of highly prone to earthquake as two tectonic plates (the Eurasian plate and the Indo-Australian plate) meeting line passes near the boundary of this region (Fig. 2). Hence this region is considered as the highrisk zone for earthquake in Bangladesh according to BNBC (1993).

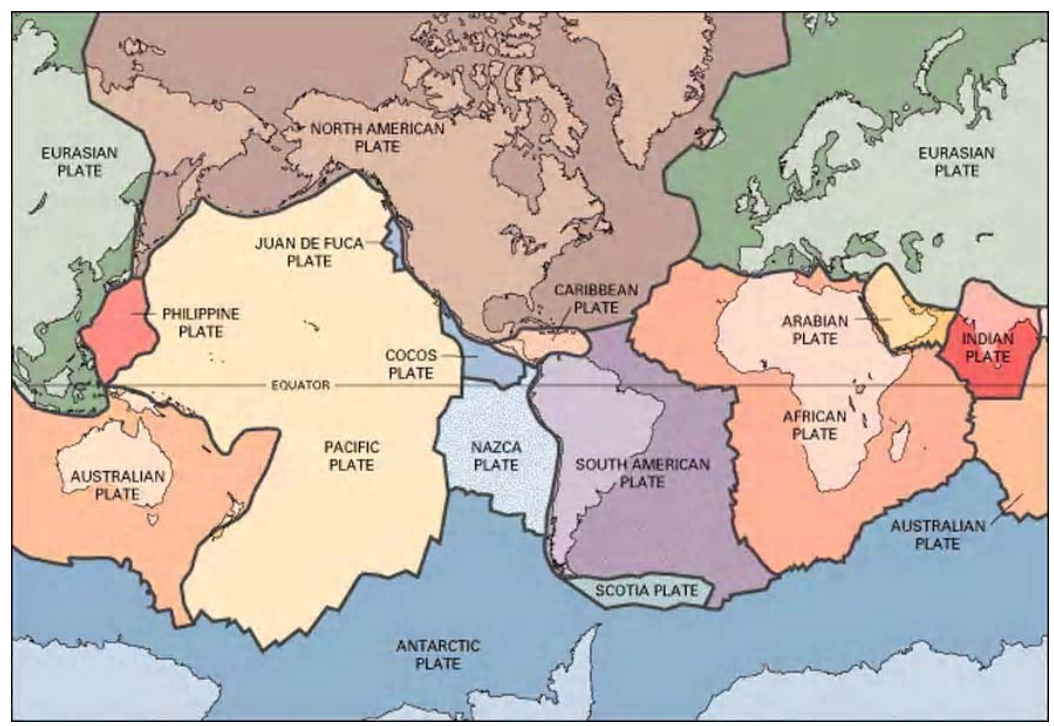

Fig. 2: Tectonic plates of the earth and the earthquake zones (USGS, 2003) 
Moreover, Sylhet is a densely populated area and if some earthquakes of high magnitude occur along the region, it will cause severe damage to the life and properties. Destruction of hills in the region is thus a suicidal form of act, only exaggerating the possibility for some severe earthquake in near future.

For precipitation, lifting of moist air mass is necessary for condensation into droplet and cloud formation (Subramanya, 1994). In this case hills act as a barrier, where the moist air, after being obstructed, lift upward and gradually loose its temperature to condense enough to form cloud. This is the main reason of the high intensity of rainfall at the Sylhet region. Due to destruction of hills, now moist air will not be obstructed such a way, and the amount of rainfall in Sylhet region is possible to be decreased considerably. The phenomenon has already been observed and mentioned in previous section (Table1). This will result in a massive change in the eco-system of tea plantation, which requires heavy rainfall. On the other hand, the moist air that blows from south will now move to the northern border hilly region Meghalaya of India, causing more rainfall there. This upstream heavy rainfall can cause for increased flash flood along Sylhet that is explained in the following section.

It is found that naturally covered surface, balance heat energy budget. Extra energy absorbed by the texture of subsurface soil and ensures a balance between day and night temperatures (Singh, 1997). Due to hill cutting, uncovered or deforested land surface breaks this balance and shows desert like weather, i.e. more temperature at day and less temperature at night. Also, unobstructed air movement from the north in winter may increase the intensity of coldness, and affect the other parts of the country. Moisture in the air may reduce due to the lack of evapo-transpiration from vegetation and plant community, and due to reduction of rainfall. Biotic community may not adjust themselves in such an abrupt changing climatic condition of varying temperature and moisture availability.

After precipitation, water from different places comes to the nearest rivers, channels etc which is called runoff. Forests or vegetation cover of the land surface make this runoff movement slower with less erosion of soil. On the other hand, soil erosion from an exposed surface is at a much higher rate with higher velocity of runoff flow and less cohesive force between soil particles. In this connection landslide may also occur for those exposed or half cut hills (Fig. 3), due to instable slope condition.
The eroded soil ultimately comes into the rivers and wetlands as runoff. Here they gradually start to settle, reducing the effective depth of water bodies. Huge siltation has already been a big problem for Bangladeshi rivers. Due to such excessive siltation, the frequency of floods in monsoon period increases and reduces the storage capacity of rivers in winter. Wetlands like Haor and Bills etc also getting silted and destroy the ecosystem of vast aquatic flora and fauna.

The region from which a river collects its water from rainfall is known as its catchment. For a particular river, catchment is determined from the land slope. As shown in Fig. 4, normally the hills act as divide between two river catchments. Now if the hills are being cut, then the land slope pattern of the region changed. As a result water availability at different rivers also changes so that flooding may occur in one river while the other becomes dry.

River cross-section builds up based on the catchments pattern and the amount of rainfall over it. If rainfall in Sylhet region decreases and Meghalaya region increases, for the upstream cross sections of the rivers in the Sylhet region, this excess flow will appear as unusual over the capacity of the river cross sections, causing flash flood. It has been reported by Bangladesh Water Development Board (BWDB) that the number of flood increases nowadays in this region. Also deforestation and resulting accelerated rate of soil erosion, which increases the sediment load of rivers, will increase the frequency and dimension of floods.

After precipitation over land surface, the amount of water flow over the ground is termed as runoff, and the rest seep into the ground is known as infiltration. At the forested or covered areas, the amount of infiltration is more than uncovered areas. As hill cut increase deforestation, infiltration will decrease, which in the long run will decrease the recharge of ground water. Lowering ground water table has already been detected from some experiments by the Public Health Engineering Department (DPHE) of Sylhet (personal communication with DPHE).

Soil quality of the hilly region of Bangladesh is mainly Acidic. More soil erosion and rapid runoff takes the hilly soil to the river as sediment load so that river water becomes acidic. Highly acidic or saline conditions are often injurious for plant growth and microorganisms. So, it may cause harm to the aquatic ecosystem of the surrounding rivers. 

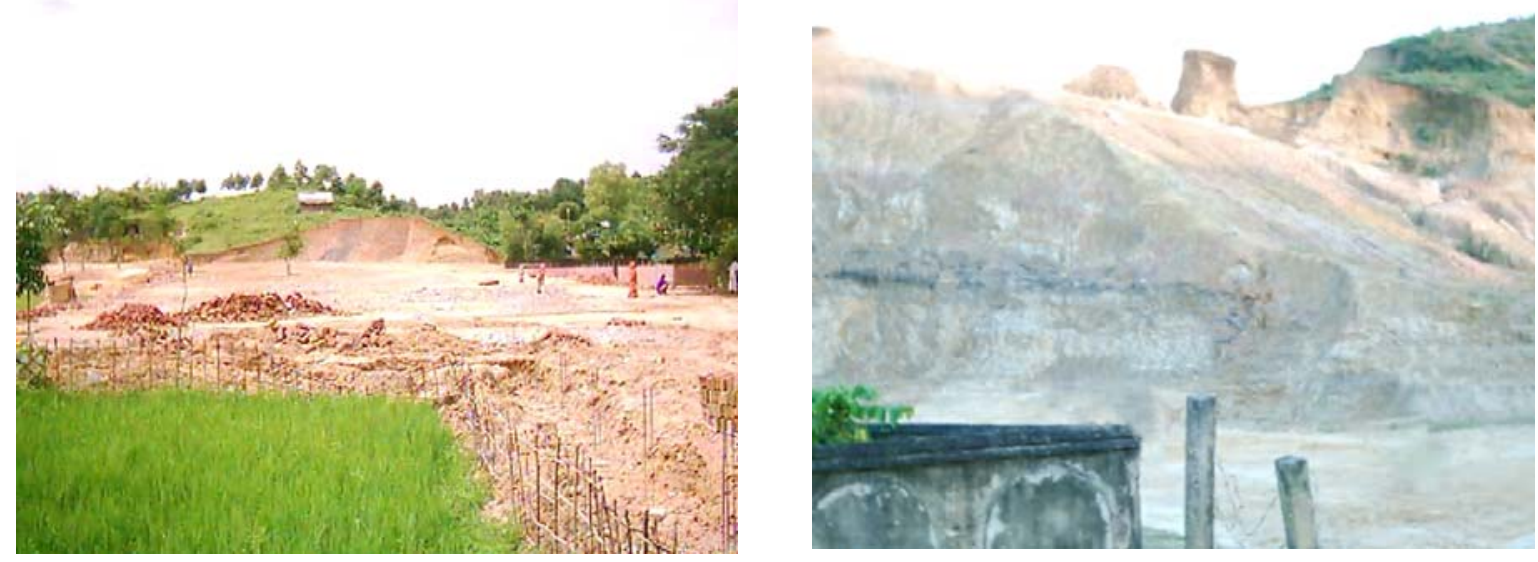

Fig. 3: Destruction of hills in different forms

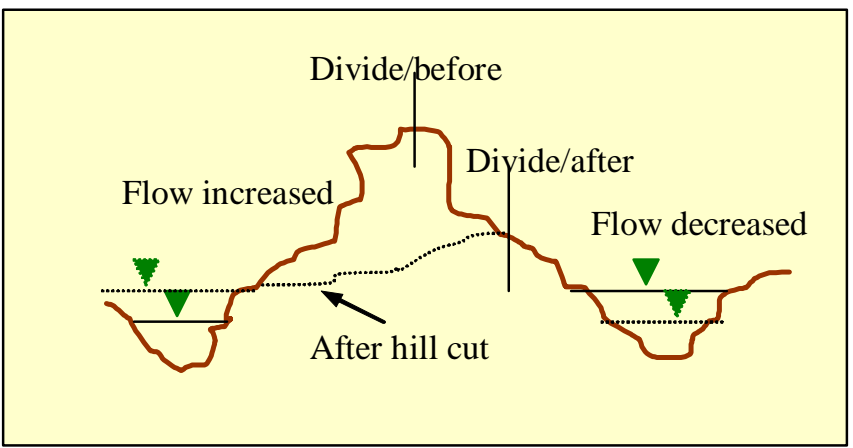

Fig. 4: Change in catchment characteristics and river flow volume after cutting a hill

\section{DISCUSSION AND CONCLUSION}

From the above discussion it is clear that the extent of the hill cutting problem in the Sylhet region is a matter of concern that needs some special attention to be paid. Such an indiscriminate destruction of hills in the region will result in drastic consequence on its nature and ecosystem threatening life and properties. Some of the most serious impacts that are of special concern for the region are change in climatic condition and drainage pattern, desertification, deforestation, increase in flood frequency and impact on biodiversity, possibility of earthquake occurrence etc. Hill cutting is the kind of crime whose impact will be far-reaching, to be felt over centuries.

The paper mainly aimed at unveiling the situation with specific causes, extent and probable impacts; detail proposal for stopping hill cutting has not been proposed here but needs some further studies. The authority of this region can start a separate department aiming to prevent destroying of hills and preserve the natural resources.

This department can monitor the issue closely and take necessary measures to protect the hills from its abusive use. However, in a nutshell it can be proposed that sophisticated method for monitoring hill cutting including GIS based arial photograph, better clarification of laws, restricting some areas strictly not permitted to cut, increasing public awareness about the consequence of abusive destruction of natural morphology, consultation with experts and including them in the permission committee, studying advanced technologies to use hills for beneficial purposes without much hampering its natural condition etc might be some measures to prevent hill cutting and resulting impacts. 
Md. Sirajul Islam, et al.

Hence immediate action is required for the conservation of the hills and hillocks, so that people of Sylhet region can save themselves from the future revenge of nature.

\section{REFERENCES}

Anonymous (2003). United States Geological Survey, Website information.

Bangladesh National Building Code (BNBC),(1993). Housing and Building Research Institute, Dhaka, Bangladesh.

DOE, A compilation of environmental laws, (2002). By the Department of Environment (DOE) and Bangladesh Environment Management Project. Dhaka, Bangladesh.
Gerrard, J., (1990). Mountain Environment. MIT Press, Cambridge.

Harun, R., (1991). Geography of Bangladesh, $2^{\text {nd. }}$ edition, University Press Ltd., Dhaka, Bangladesh.

Hugh, B., (2002). Land use and land use planning in Bangladesh. University Press Ltd., Dhaka, 554.

Paul, C., (1995). Ecology 2. John Wiley and Sons, 688, New York, USA.

Report of the Sylhet Disaster Forum (SDF), 2001.

Subramanya, K., (1994). Engineering Hydrology. Tata McGraw Hill, New Delhi, India.

Savindra, S., (1997). Environmental Geography. India. 